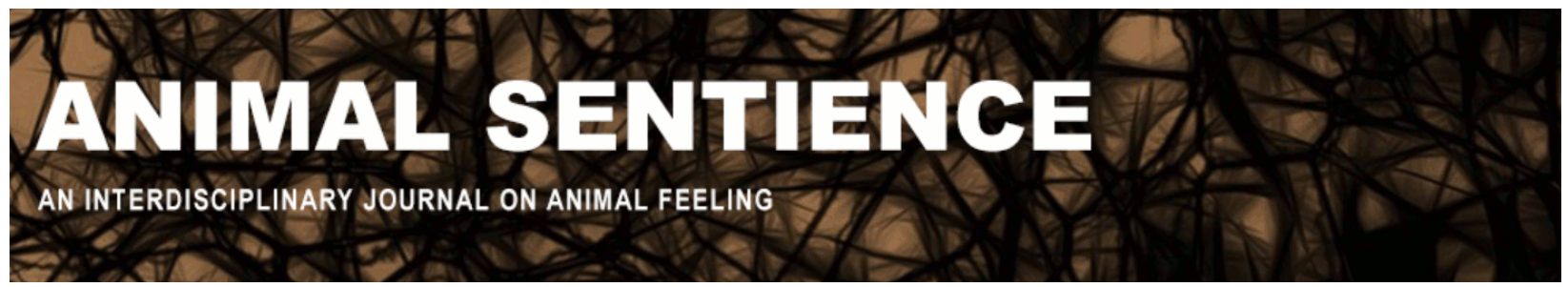

lotchev, Ivaylo Borislavov and Costa, Kauê Machado (2019) Animal cognition: Quantity has a quality of its own. Animal Sentience 23(44)

DOI: $10.51291 / 2377-7478.1430$

Date of submission: 2019-03-18

Date of acceptance: 2019-04-07

(c)

This article has appeared in the journal Animal

Sentience, a peer-reviewed journal on animal

cognition and feeling. It has been made open access,

free for all, by WellBeing International and deposited

in the WBI Studies Repository. For more information,

please contact

wbisr-info@wellbeingintl.org.

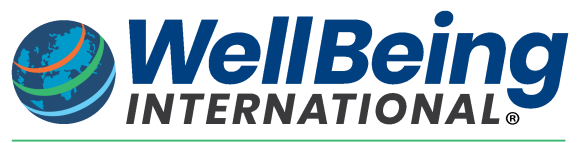

SOLUTIONS FOR PEOPLE, ANIMALS AND ENVIRONMENT 


\title{
Animal cognition: Quantity has a quality of its own
}

Commentary on Chapman \& Huffman on Human Difference

\author{
Ivaylo Borislavov lotchev \\ Department of Ethology \\ Eötvös Loránd University, Budapest, Hungary \\ Kauê Machado Costa \\ National Institute on Drug Abuse Intramural Research Program \\ National Institutes of Health, Baltimore, MD
}

\begin{abstract}
Chapman \& Huffman's moral analysis fails to prove that the exploitation of animals or the environment is causally connected to beliefs about human capacities. Their exposition of the philosophical interpretations of animal cognition ignores historical context and confounds different levels of analysis. Their analysis of the scientific literature, from which they conclude that humans should not be considered as different from other animals, does not take into account many recent psychological and neuroscientific developments and rests upon a flawed understanding of the relationship between gradual and categorical differences, misrepresenting the two as mutually exclusive concepts.
\end{abstract}

Ivaylo Borislavov lotchev works as a PhD
student/data-scientist at the Ethology Department
of the Eötvös Loránd University in Budapest,
Hungary. His areas of research include sleep-
physiology, perception and hierarchical social
organization in dogs, as well as higher social
cognition in dogs and humans. Website

Kauê Machado Costa is a neuroscience researcher at the National Institute on Drug Abuse Intramural Research Program in Baltimore, Maryland. His research focuses on how dopamine signals and cortical neuronal activity represent behaviorally relevant information and support different aspects of learning. Website
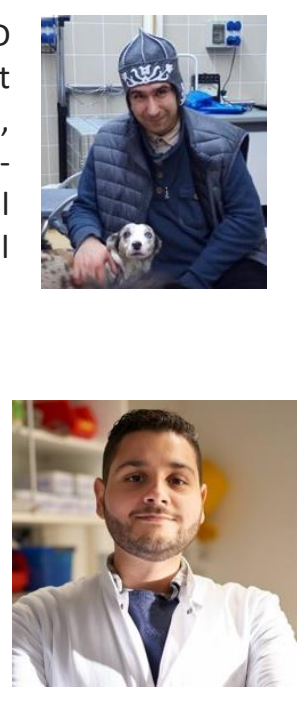

Chapman \& Huffman (2018) (C \& H) tackle the profound question of how humans differ from other species. They show laudable intellectual initiative in addressing, at once, philosophical, ethical and scientific questions associated with the topic. The sheer number of commentaries on this target article attests to the latent demand for this integrative and intellectually rich approach in modern academia. We find that their line of reasoning has several key flaws, however, that belie their main conclusions. 
C \& $\mathrm{H}$ attribute specific intentions to the targets of their criticism. Particularly when referring to enlightenment philosophers, such as Descartes or Malebranche, and the JudeoChristian tradition, C \& H suggest that ideas of human exclusivity necessarily originate from intentional justifications for animal exploitation and cruelty. This is a strawman strategy, ignoring the broader context of these works. Both the Judeo-Christian canon and the humanist oeuvre of the post-medieval period do indeed glorify humanity. It is more parsimonious to assume, however, that the main objective was to elevate the value of human life and the standards of human interactions, culminating in the conceptualization of human rights.

Other philosophers in this tradition, not attributing more than instincts to animals, were explicitly opposed to animal cruelty. Kant (1797) wrote that "violent and cruel treatment of animals ... dulls [the human's] shared feeling of their pain and so weakens and gradually uproots a natural predisposition that is very serviceable to morality in one's relations with other human beings" (for an in depth analysis, see Denis, 2000). This passage exemplifies the focus on improving human moral welfare and suggests that viewing animals as (intellectually) inferior is not antagonistic to the moral rejection of animal mistreatment. It is also not unanimously agreed that Descartes should be read as denying sentience to animals (Erdenk, 2013). Although most philosophers historically did not expect or search for non-human intellect, an objective characterization of animal sentience was also not a priority for most of human existence. Nonhuman behavior was only a topic in the sense that it framed ideas about what it means to be human.

It is true that in the transition between philosophy and natural science, multiple contemporary notions were incorporated into the scientific canon with little regard to their empirical validation, including the assumption that animals were incapable of internal thought or emotion. However, one interpretation of this process would be that historical prejudices about animal cognition provided essential "null hypotheses" for the early naturalists and later for experimental psychologists. In the context of research, a null hypothesis that is maximally pessimistic about the internal lives of animals is very useful in creating strong experimental designs. The utility to be skeptical about animal cognition and emotion in conducting rigorous research on these matters has been strongly argued for by researchers who otherwise firmly believe that animals have a rich mental life (Dawkins, 1993). Hence, regarding the development of cognitive science, it is inadequate to reduce the assumption of human uniqueness and exclusivity to a purely moral issue.

There is also the question of what is the origin of the moral primacy attributed to humans over other animals. Not only is the prioritization of other humans not equal to the prioritization of profit over environment, but C \& $\mathrm{H}$ do not convincingly show that it derives from belief in superior capacities. This is explicit in archetypal stories of humans facing superior entities. Ancient mythology is rife with tales of conflicts between humans and gods, and the modern science fiction genre often focuses on human struggles against alien invasions, robot upheavals and other narratives of battles against technologically, physically and intellectually superior out-group agents. How can humans be the heroes of these stories if the moral standing of humanity derives exclusively from the assumption of superior capacities? One interpretation is that this is a manifestation of kin-prioritization, i.e., we attach greater moral value to those who are more closely related to us (in-group), without much regard for our capacity relative to members of the out-group. This is a universal feature of social behavior that has been proposed to provide 
evolutionary benefits through inclusive fitness (Hamilton, 1964), although the underlying mechanisms are often based on imprecise proxies for relatedness, such as early familiarity (BenAmi Bartal, Rodgers, Bernardez Sarria, Decety, \& Mason, 2014). It is conceivable that the sense of tribal or ethnic supremacy observed in humans, which has historically resulted in episodes of deplorable cruelty to out-group members, is an aggravated and semi-pathological facet of kinprioritization, which $\mathrm{C} \& \mathrm{H}$ correctly point out to be an impediment to moral growth and civilization.

Concerning the scientific aspect of the topic, C \& $\mathrm{H}$ recreate an outdated problem. Most of the theories about human uniqueness they discuss (e.g., "Man the Toolmaker," Carlyle, 1831) date from the 19th century and were based on categorical interpretations of specific behaviors. These were often concerned solely with externally observable behaviors such as the intake of medicine, an idea attributed to the physician Sir William Osler (Ravenel, 2008). C \& W apply this framework to the comparison of human and wasp societies with no regard for the internal mechanisms driving the agents within these groups. The 20th century cognitive revolution, which disrupted the tradition of treating behavior as the input-output of a black box, is ignored, despite its role in refuting the view of animals as purely instinctive (Tolman, 1948). In itself, a classical behaviorist outlook is methodologically legitimate, but on the few occasions $\mathrm{C} \& \mathrm{H}$ allude to the "inside of the black box," the two different levels of analysis are not clearly outlined. This frames very different observations and thoughts as if they were applying to the same questions, which is not necessarily correct. We adopt this distinction below, referring to these levels as the first (external, categorical) and second (mechanistic, causal) levels of analysis, since this is also the order in which they have historically dominated psychological research (Pekala, 2013).

$\mathrm{C} \& \mathrm{H}$ imply that our constantly changing theories about what makes humans unique are in themselves an argument against human uniqueness. It is safer to say that our understanding of human-animal differences has improved and become more nuanced as we have moved, historically, from the first to the second level of analysis. This is comparable to the change imposed on the concept of gravity when classical Newtonian gravitational theory was superseded by Einstein's general theory of relativity (Whittaker, 1943).

Gravity and human uniqueness share the feature that even on the first level of analysis, they are unquestionable. The fact that humans out-compete other animals in their capacity for intentional manipulation of the environment is ironically also recognized by $\mathrm{C} \& \mathrm{H}$ when they refer to the ecological impacts of human activity. They cite statistics showing that, as a species, we have increased global extinction levels by three orders of magnitude, and that several other authors have compared the effects of human civilization to natural mass extinctions events (Ceballos, Ehrlich, \& Dirzo, 2017; Crutzen, 2002). This is quite a remarkable feature for a single vertebrate species and is only one example of the unparalleled capabilities of humans to mold their environment according to their will. This implies that the moral of $\mathrm{C} \& \mathrm{H}$ 's argument is inverted: our moral obligation towards other species derives not from our similarity to them, but rather from the responsibility that is inherent in the superior cognitive capacities that make us different. It is exactly because we are uniquely capable of cruelty and of exacting almost incalculable harm to the environment that we have the moral obligation to refrain from both.

C \& H (2018) also seem to ignore the current state of scientific debate on the topic at hand. Strong theoretical and empirical support has accumulated that emotion (De Waal, 2008; McLean, 1990; Panksepp, 2011) and the ability to think and abstractly categorize information (Grandin, 
1997; Köhler, 1956; Pepperberg, 2006; Tolman, 1948) are functions that are evolutionarily conserved across many species. Although the question of whether most animals have sentient experiences of their own is still a debated topic (Dennett, 1997), much of this remaining controversy has to do with the difficulty of grasping consciousness in general (Chalmers, 1996) rather than a blanket denial of animal sentience.

The current scientific evidence points to gradual, yet distinctive, differences in shared physiological and psychological structures between humans and animals. These differences compound and feed back onto each other, producing supra-additive effects on cognitive capacity. Language is a key example, although the extent of its impact on cognition is still debated (Laplane, 1992). There are currently at least three schools of thought about how language ties with cognition. There is an influential theory that language is an essential mechanism for establishing declarative autobiographical memories and abstract thought, which in turn are crucial for individual conscious experience (Dennett, 1993, 1997). Alternatively, non-verbal mechanisms for declarative thought have been proposed as well (Grandin, 1997; Köhler, 1956), while a third, intermediate position holds that some forms of thought we observe in animals are the expression of proto-language or proto-syntax (Hauser, Chomsky, \& Fitch, 2010). The consensus, however, is that human linguistic ability far outcompetes that of other animals in terms of informational representation. The maximum performance of dogs and parrots observed so far does not exceed the understanding or use of two-word sentences (Pepperberg, 2006; Ramos \& Ades, 2012), and even closely-related primates of the human lineage never reach human levels of syntactic proficiency (Hauser et al., 2010; Snowdon, 1990). There are, in addition, conjectures that processes similar to domestication, including attenuated stress responsiveness, have affected the evolution of human cognition (Hare, Wobber, \& Wrangham, 2012; Leach, Groves, O'Connor, Pearson, \& Zeder, 2003; Pörtl \& Jung, 2017).

In neuroscience, we have similarly been moving away from debating whether relevant macro-structures are shared (Uylings, Groenewegen, \& Kolb, 2003) toward observing more subtle, but crucial, differences. Humans display a series of synergistic neurobiological adaptations that are correlated with higher cognitive capacity. For example, compared to those of rodents, human cortical neurons display a number of specific adaptations in dendritic information processing (Beaulieu-Laroche et al., 2018; Kalmbach et al., 2018), some of which correlate with IQ scores (Goriounova et al., 2018).

One interesting common feature of current evidence on human-specific brain characteristics is that, in agreement with $\mathrm{C} \& \mathrm{H}$, the evolutionary mechanisms that led to them are not extraordinary. Indeed, almost all neurobiological traits that are exceptional in humans seem to be versions of evolutionary trends observed throughout the primate lineage. A basic example is the number of neurons in the cerebral cortex: while humans do indeed have the largest number of cortical neurons of all studied primates, this measure falls exactly in line with the expected number for our body size within that clade (Herculano-Houzel, 2009). Another example is the degree of dopaminergic innervation of the cerebral cortex, which is denser and more widespread in humans than in other primates, but in turn is also greater in primates than in other mammals studied (Berger, Gaspar, \& Verney, 1991; Raghanti et al., 2008). Given that dopaminergic modulation underlies multiple forms of learning, including the creation of associative models of the external world, the increase in cortical dopaminergic innervation has been proposed as an underlying mechanism for the higher learning capacity observed in humans 
and other primates (Previc, 1999; Sharpe et al., 2017). Finally, humans do display at least some unique neurobiological features even when compared to other great apes, including the presence of subpallially derived dopamine-synthesizing interneurons in the striatum that are absent in other African great apes (Sousa et al., 2017).

Differences in the degree of proficiency of shared capacities or in specific properties of biological substrates should not be dismissed as mere nuances. C \& H reject categorical differences based solely on discoveries that some animals on certain occasions exhibit forms of behavior that were once thought to be uniquely human. However, even if every non-human animal were able to execute all forms of behavior that humans exhibit, that would still not preclude a categorical distinction between the two groups. Both a toddler and a marathon runner are capable of bipedal ambulation, and both a wheelbarrow and a semi-trailer truck can be used to carry cargo, but a judicial observer can clearly establish different categories for the latter and the former in either example.

As first pointed out by Hegel (Bukharin, 1925; Carneiro, 2000) and then expanded by Marx (1889) and Engels (1940), qualitative changes in nature are always generated by the gradual addition or subtraction of quantitative changes. This has also been recognized as a hallmark of biological evolution since Darwin (1859). Current evidence does suggest that in every measured ability, humans differ from non-human animals only by degree. Yet it is crucial to recognize that large quantitative differences in cognitive and physical capacities can also produce reliably distinct categories, and that recognizing the reality of this categorization is not only morally sound but also a scientific imperative.

Acknowledgements: We would like to thank Enikő Kubinyi, Ádám Miklósi, Gilles van Luijtelaar, Hein van Schie, Maximilian Krys and Leonora Lychko for thoughtful discussions on the topic and commentaries on this manuscript.

Funding and conflicts of interest: Ivaylo lotchev declares no conflict of interests and wrote this commentary while funded by European Research Council (ERC) under the European Union's Horizon 2020 research and innovation program (Grant Agreement No. 680040). Kauê Machado Costa is supported by the Intramural Research Program at the National Institute on Drug Abuse. The opinions expressed in this article are the authors' own and do not reflect the view of the NIH/DHHS.

\section{References}

Beaulieu-Laroche, L., Toloza, E. H. S., van der Goes, M. S., Lafourcade, M., Barnagian, D., Williams, Z. M., Eskandar, E. N., Frosch, M. P., Cash, S. S., \& Harnett, M. T. (2018). Enhanced dendritic compartmentalization in human cortical neurons. Cell, 175(3), 643-651.e14.

Ben-Ami Bartal, I., Rodgers, D. A., Bernardez Sarria, M. S., Decety, J., \& Mason, P. (2014). Prosocial behavior in rats is modulated by social experience. eLife, 3, e01385.

Berger, B., Gaspar, P., \& Verney, C. (1991). Dopaminergic innervation of the cerebral cortex: Unexpected differences between rodents and primates. Trends in Neurosciences, 14, 21-27.

Bukharin, N. (1925). Historical materialism, a system of sociology. New York: International Publishers.

Carlyle, T. (1831). Sartor resartus: The life and opinions of Herr Teufelsdrockh.

Carneiro, R. L. (2000). The transition from quantity to quality: A neglected causal mechanism in 
accounting for social evolution. Proceedings of the National Academy of Sciences of the United States of America, 97(23), 12926-12931.

Ceballos, G., Ehrlich, P. R., \& Dirzo, R. (2017). Biological annihilation via the ongoing sixth mass extinction signaled by vertebrate population losses and declines. Proceedings of the National Academy of Sciences of the United States of America, 114(30), E6089-E6096.

Chalmers, D. J. (1996). The conscious mind: In search of a fundamental theory. Oxford University Press.

Chapman, C. A., \& Huffman, M. A. (2018). Why do we want to think humans are different?. Animal Sentience 23(1).

Crutzen, P. J. (2002). Geology of mankind. Nature, 415(6867), 23.

Darwin, C. (1859). On the origin of species by means of natural selection, or, the preservation of favoured races in the struggle for life. London: John Murray.

Dawkins, M. S. (1993). Through our eyes only? The search for animal consciousness. Oxford University Press.

De Waal, F. B. M. (2008). Putting the altruism back into altruism: The evolution of empathy. Annual Review of Psychology, 59, 279-300.

Denis, L. (2000). Kant's conception of duties regarding animals: Reconstruction and reconsideration. History of Philosophy Quarterly.

Dennett, D. C. (1993). Consciousness explained. Penguin.

Dennett, D. C. (1997). Kinds of minds towards an understanding of consciousness. Biochemical Education, 25(3), 185-186.

Engels, F. (1940). Dialectics of nature. New York: International Publishers.

Erdenk, E. A. (2013). Descartes' account of feeling of pain in animals. FLSF, 201-210.

Goriounova, N. A., Heyer, D. B., Wilbers, R., Verhoog, M. B., Giugliano, M., Verbist, C., Obermayer, J., Kerkhofs, A., Smeding, H., Verberne, M., Idema, S., Baayen, J. C., Pieneman, A. W., de Kock, C. P. J., Klein, M., \& Mansvelder, H. D. (2018). Large and fast human pyramidal neurons associate with intelligence. eLife, 7.

Grandin, T. (1997). Thinking the way animals do. Western Horseman, 140-145.

Hamilton, W. D. (1964). The genetical evolution of social behavior, I and II. Journal of Theoretical Biology, 7, 1-52.

Hare, B., Wobber, V., \& Wrangham, R. (2012). The self-domestication hypothesis: Evolution of bonobo psychology is due to selection against aggression. Animal Behaviour, 3, 573-585.

Hauser, M. D., Chomsky, N., \& Fitch, W. T. (2010). The faculty of language: What is it, who has it, and how did it evolve? In The evolution of human language: Biolinguistic perspectives (pp. 14-42).

Herculano-Houzel, S. (2009). The human brain in numbers: A linearly scaled-up primate brain. Frontiers in Human Neuroscience, 3.

Kalmbach, B. E., Buchin, A., Long, B., Close, J., Nandi, A., Miller, J. A., ... Ting, J. T. (2018). $\underline{\text { h- }}$ channels contribute to divergent intrinsic membrane properties of supragranular pyramidal neurons in human versus mouse cerebral cortex. Neuron, 100(5), 1194-1208.

Kant, I. (1797). The metaphysics of morals. In A. W. Wood (Ed.), Immanuel Kant: Practical philosophy (pp. 353-604).

Köhler, O. (1956). Thinking without words. In Proceedings of the 14th International Congress of Zoology (pp. 75-88). Copenhagen. 
Laplane, D. (1992). Thought and language. Behavioural Neurology, 5(1), 33-38.

Leach, H. M., Groves, C., O’Connor, T., Pearson, O., \& Zeder, M. A. (2003). Human domestication reconsidered. Current Anthropology, 44(3), 349-368.

Marx, K. (1889). Capital: A critical analysis of capitalist production. F. Engels (Ed.). London: Swan Sonnenschein \& Co.

McLean, P. (1990). The triune brain in evolution. Springer.

Panksepp, J. (2011). The basic emotional circuits of mammalian brains: Do animals have affective lives? Neuroscience and Biobehavioral Reviews, 35, 1791-1804.

Pekala, R. J. (2013). The cognitive revolution in psychology. In quantifying consciousness (pp. 5371).

Pepperberg, I. M. (2006). Cognitive and communicative abilities of Grey parrots. Applied Animal Behaviour Science, 100(1-2), 77-86.

Pörtl, D., \& Jung, C. (2017). Is dog domestication due to epigenetic modulation in brain? Dog Behavior, 2.

Previc, F. H. (1999). Dopamine and the origins of human intelligence. Brain and Cognition, 41(3), 299-350.

Raghanti, M. A., Stimpson, C. D., Marcinkiewicz, J. L., Erwin, J. M., Hof, P. R., \& Sherwood, C. C. (2008). Cortical dopaminergic innervation among humans, chimpanzees, and macaque monkeys: A comparative study. Neuroscience, 155(1), 203-220.

Ramos, D., \& Ades, C. (2012). Two-item sentence comprehension by a dog (Canis familiaris). PLOS ONE, 7(2).

Ravenel, M. P. (2008). The life of Sir William Osler. American Journal of Public Health, 15(10), 904-906.

Sharpe, M. J., Chang, C. Y., Liu, M. A., Batchelor, H. M., Mueller, L. E., Jones, J. L., Niv, Y., \& Schoenbaum, G. (2017). Dopamine transients are sufficient and necessary for acquisition of model-based associations. Nature Neuroscience, 20(5), 735-742.

Snowdon, C. T. (1990). Language capacities of nonhuman animals. American Journal of Physical Anthropology, 33(11S), 215-243.

Sousa, A. M. M., Zhu, Y., Raghanti, M. A., Kitchen, R. R., Onorati, M., Tebbenkamp, A. T. N., ... Sestan, N. (2017). Molecular and cellular reorganization of neural circuits in the human lineage. Science, 358(6366), 1027-1032.

Tolman, E. C. (1948). Cognitive maps in rats and men. Psychological Review, 55(4), 189-208.

Uylings, H. B. M., Groenewegen, H. J., \& Kolb, B. (2003). Do rats have a prefrontal cortex?

Behavioural Brain Research, 146, 3-17.

Whittaker, E. T. (1943). Aristotle, Newton, Einstein. Science, 98(2542), 249-254. 